\title{
De ideias e lugares: uma história do liberalismo econômico no Brasil oitocentista
}

Raphael Castro Martins ${ }^{1}$ Ivan Colangelo Salomão

RESUMO: o liberalismo encontrou no Brasil uma realidade distinta daquela em que a ideologia surgiu, nos países europeus. Uma sociedade escravista, cujas relações sociais baseavam-se no favor, não poderia locupletar-se de ser exatamente liberal, ainda que o fosse em termos econômicos. Extrapolando a polêmica acerca da adaptabilidade do liberalismo nos trópicos, este trabalho tem por objetivo sistematizar algumas das principais características do liberalismo econômico no Brasil do século XIX. Para tanto, analisou-se o pensamento de três proeminentes autores liberais, a inserção do país na divisão internacional do trabalho e, por fim, o debate monetário travado naquele momento histórico.

PALAVRAS-CHAVE: Liberalismo; História Econômica; Brasil

\section{On ideas and places: a history of economic liberalism in Brazil of nineteenth century}

ABSTRACT: liberalism in Brazil encountered a different reality from the one in which it raised in European countries. A slavery society, in which social relations were based on favour, could not be a defined as a liberal society exactly. Beyond the polemic about the adaptability of liberalism in the tropics, this paper aims to systematize some of the main features of economic liberalism in Brazil during the nineteenth-century. In order to achieve this goal, it is analyzed three prominent liberal authors's thought, the insertion of the country in the international division of labor, and the monetary debate held at that historical moment.

KEYWORDS: Liberalism; Economic History; Brazil

JEL Code: B12

\section{Introdução}

O liberalismo estabeleceu-se no Brasil em circunstâncias distintas da realidade em que fora concebido na Europa. Se comparada à exploração da América hispânica, a estratégia de colonização portuguesa na América robusteceu ainda mais os óbices para que a ideologia burguesa se afirmasse em território brasileiro. Este retardamento em se

\footnotetext{
1 Bacharel em Economia pela Universidade Federal do Rio Grande do Sul. E-mail: rapahaelcm@gmail.com

2 Professor da Faculdade de Ciências Econômicas e do Programa de Pós-Graduação em Economia da Universidade Federal do Rio Grande do Sul (PPGE/UFRGS). E-mail: ivansalomao@gmail.com
} 
debater e avaliar a funcionalidade do liberalismo fez com que o Brasil se tornasse um dos países mais refratários ao ideário liberal na América Latina (LYNCH, 2007).

Foi somente durante o século XIX, especialmente após a emancipação política em relação a Lisboa, que o liberalismo encontrou no Brasil a possibilidade de locupletar-se como ideologia dominante. Se durante o período de vigência do modelo primário-exportador do país independente - de 1822 até o início da quarta década do século XX - o liberalismo se fez presente ao menos no que tocava à política comercial, não se pode afirmar que, do ponto de vista político e social, o país viveu, de fato, sob a égide de um modelo liberal. Daí a plausibilidade da conhecida tese de Schwarz (1992), para quem o liberalismo, no Brasil, era uma ideologia "fora de lugar".

Extrapolando a polêmica acerca da adaptabilidade do liberalismo nos trópicos, este trabalho tem por objetivo sistematizar algumas das principais características do liberalismo econômico no Brasil do século XIX. Ideologia responsável pelo modelo de inserção na divisão internacional do trabalho levada a cabo durante o Segundo Reinado, as ideias liberais só foram suplantadas quando do paulatino surgimento de uma nova estratégia de desenvolvimento tipicamente latino-americana: o nacionaldesenvolvimentismo.

Um trabalho sobre a economia política liberal vigente no período supradelimitado poderia abarcar diversos vetores. Optou-se, como instrumento metodológico neste artigo, analisar, em primeiro lugar, os aspectos basilares do pensamento de três de seus principais veiculadores no período (José da Silva Lisboa, Tavares Bastos e Joaquim Murtinho). A seguir, discorre-se acerca da posição do Brasil na divisão internacional do trabalho, como economia provedora de poucos bens agrícolas para os países centrais que passavam por suas respectivas revoluções industriais. Por fim, analisam-se os meandros do debate monetário travado entre as principais lideranças políticas do segundo reinado.

\section{O ideário liberal durante o "Iongo século XIX"}

Durante o século XIX ainda não haviam desenvolvido desenvolvidas ideias econômicas autóctones propriamente ditas em território brasileiro. Naquele momento, o debate econômico circunscrevia a esfera de atuação de burocratas, empresários, políticos e homens públicos em geral; que versavam sobre a temática nas entrelinhas de seus discursos e obras. Essa realidade não significa, porém, que as ideias liberais 
daquele século não tenham embasado a pré-história do ideário ortodoxo ${ }^{3}$ que seria posteriormente desenvolvido no país.

Visando a analisar os caminhos do liberalismo brasileiro no decorrer do século supracitado, utilizar-se-ão das leituras de três proeminentes autores os quais, embora tenham focado suas análises em assuntos distintos - o que se justifica pelo hiato temporal em que viveram e atuaram -, buscar-se-á, dessa forma, apresentar um panorama geral das abordagens liberais durante o período aqui analisado.

José da Silva Lisboa, o visconde de Cairu, foi um dos mais destacados defensores e divulgadores da doutrina liberal do início do século XIX. Tal constatação pode ser aferida pela insígnia a ele posteriormente outorgada: o de primeiro “economista" brasileiro. Nascido em 1756 na cidade de Salvador, Cairu participou tanto da transição brasileira da Colônia para Império, quanto das diversas agitações civis que ocorreram dentro do território brasileiro, como a Confederação do Equador e a Revolução Farroupilha, que teve início no ano de sua morte. Diante de tal agitação social surgiu um Cairu que, segundo Paim (1998), chega a abandonar sua obra de tratadista de direito para se tornar um "defensor panfletário", no sentido amplo do termo, do liberalismo econômico.

Proeminente advogado dos benefícios oriundos do livre-comércio e grande apoiador da abertura dos portos patrocinada por d. João VI a partir de 1808 , teve como pauta principal dos seus discursos a defesa da liberdade alfandegária. Inspirado pelos escritos de Adam Smith, de quem fora discípulo direto na época em que esteve na Inglaterra, Cairu propôs-se a tentar influenciar as convicções dos comerciantes da época, os quais, acostumados às condições monopolistas, teriam que se adaptar celeremente à nova realidade concorrencial pós-1808. Tais esforços, porém, não lograram o efeito desejado, conforme reconheceu o próprio autor:

O suplicante aprecia, quanto deve a suas graças da cadeira de ciência econômica; e, em obediência à Ordem expedida por Vossa excelência, passou logo da Bahia para esta capital. Mas tem observado que o público não conhece a importância daquela ciência, nem está preparado para ela com os estudos competentes, e está cheio de errôneas preocupações a esse respeito (LISBOA apud FARIA JUNIOR, 2008, p. 126).

\footnotetext{
${ }^{3}$ Faz-se fundamental ressalvar as diferenças conceituais entre liberalismo e ortodoxia. Conquanto sejam aqui utilizados como termos aparentemente substituíveis, o conceito de ortodoxia pode se aproximar do liberalismo nos termos empregados por Fonseca (2010, p. 425): "liberalismo econômico pode ser entendido como as teorias e práticas de política econômica adotadas pelo mainstream [...] respaldado na máxima do laissez-faire."
} 
Apesar de o foco dos escritos de Cairu ter, de fato, recaído sobre questões comerciais e produtivas, o autor também se debruçou sobre assuntos como escravidão e moralidade. De acordo com Alves (2004), ao escrever Da liberdade do trabalho, publicação póstuma de 1851, Cairu inspirou-se n'A Teoria dos sentimentos morais, de Adam Smith. Por meio dos conceitos de moralidade e civilização apropriados deste autor, arrolou algumas características básicas que para ele deveriam ser imanentes ao trabalho: racionalidade, ou seja, liberdade para realizar atividades que conviessem a sua necessidade; respeito às limitações físicas dos indivíduos; e acesso do trabalhador ao fruto de seu trabalho.

No que tange à questão da organização laboral, Cairu acreditava que por não ter acesso ao fruto de seu trabalho, o escravo não teria estímulo para produzir, comprometendo, assim, a produtividade global da economia. Não se deve atribuir tal restrição, porém, a qualquer sentimento hodierno de igualdade. Com efeito, Lisboa considerava os negros seres inferiores, os quais obstaculizavam o desenvolvimento de uma moralidade social e que, portanto, deveriam ser domesticados. Mais próximo da moralidade católica da época do que propriamente da atual moralidade liberal, Lisboa atuou como censor do Império por diversos anos, tendo considerado a Igreja Católica, ao lado do governo e do povo, um dos três pilares fundamentais da sociedade. Nesse sentido, Monteiro (2001, p. 192) argumenta que "a 'economia' de Cairu não era ainda exatamente a economia dos sonhos de muito liberal, o tradicional laissez faire [...]. A 'mão invisível' de Cairu é a mão providencial de Deus, embora ele percebesse a necessidade progressiva de substituí-la pelas mãos prudentes do governo humano".

O segundo autor cujas ideias representaram um baluarte do liberalismo na metade do século XIX foi Tavares Bastos. Consoante Silva (1999), o autor pode ser considerado um dos expoentes do pensamento liberal brasileiro na segunda parte do século XIX devido à consistência ideológica, já que se mostrava prematuramente um amplo defensor de direitos civis condizentes com o liberalismo moderno. Nascido em 1839, viveu em uma época em que os principais temas nacionais já se afastavam daqueles a que se dedicara Cairu. O foco dos trabalhos de Tavares Bastos recaía prioritariamente sobre o estabelecimento de relações funcionais de trabalho, uma vez que já se faziam ouvir, a partir dos anos 1860, as manifestações anti-escravistas que desembocariam na abolição do cativeiro décadas mais tarde. 
Nesse sentido, Tavares Bastos passou a defender conceitualmente a imigração não apenas como reposição da mão de obra escrava, mas também como meio de "democratizar o Brasil através do trabalho livre" (GUGGLIOTA, 2007). Condizente com as premissas liberais, acreditava que o Estado deveria exercer funções básicas a fim de garantir o pleno funcionamento dos mercados, dentre as quais se encontrava a incumbência de atração e acomodação de imigrantes, bem como a de execução de planos que visassem à eficiência da produção agrícola. De forma sumarizada, o autor arrolava as principais ações de que deveria ocupar-se o ente estatal para atingir estes fins: (i) adotar a cobrança de imposto territorial para coibir latifúndios improdutivos; (ii) estabelecer uma escala móvel para o preço de terras; e (iii) alterar o estatuto das terras devolutas, por ele considerada a reforma mais relevante.

O destaque que Bastos conferia à legislação fundiária devia-se ao fato de, ao considerar devolutas as propriedades que não estão sob posse privada, o governo permitia aos latifundiários avançarem sobre tais regiões, dificultando, assim, a demarcação legal das mesmas. O autor defendia ações baseadas no modelo americano, em que o Estado tomava posse das áreas despovoadas pagando as devidas indenizações, para, a partir destas áreas, formar núcleos coloniais.

Ainda assim, tal qual se afirmou a respeito das convicções de José da Silva Lisboa, não se pode alinhar suas motivações à moral liberal contemporânea. De acordo com Guggliota (2007, p. 74), Bastos não aquiescia ao intento migratório de quaisquer povos. O autor priorizava imigrantes advindos da região norte da Europa e dos Estados Unidos, negligenciado os fluxos populacionais da América Latina, uma vez que as instituições políticas e sociais desses países não haviam suplantado o pensamento retrógrado da Igreja Católica.

Por fim, o terceiro autor cujas ideias representaram o ideal liberal no fim do século XIX de forma mais aguerrida foi Joaquim Duarte Murtinho. Nascido em Cuiabá, em 1848, Murtinho foi ministro da Fazenda no governo Campos Salles, tendo se ocupado de questões expressivamente diferentes das abordadas pelos dois autores anteriores. O fato de ter vivenciado o período do Encilhamento fez com que Murtinho tenha se dedicado ao entendimento dos mecanismos monetários que resultaram na crise, bem como dos instrumentos para superá- $1 a^{4}$.

\footnotetext{
${ }^{4} \mathrm{O}$ trabalho de Luz (1980) compila discursos e escritos de Murtinho sobre os mais variados temas, desde cartas pessoais até relatórios do Ministério da Fazenda. Trata-se da obra mais completa acerca do pensamento do autor.
} 
Joaquim Murtinho formou-se intelectualmente em meio à explosão das ideias positivistas que pululavam entre os acadêmicos de sua época. Ainda assim, Murtinho abraçou o evolucionismo, doutrina que passava a circular entre os círculos da elite brasileira de forma gradativa. Essa influência inconteste ajuda a explicar a aversão que Murtinho demonstrava quanto à intervenção estatal nos mercados, já que tal interferência corrompia, a seu ver, a competição livre ao impedir que os produtores mais aptos à sobrevivência triunfassem (FARIA, 2005).

No que tange ao debate econômico propriamente dito, Murtinho apontou, no relatório do Ministério da Fazenda de 1900, três causas fundamentais da crise econômica legada por Rui Barbosa: (i) dissonância entre produção e consumo de café; (ii) discordância entre reservas de ouro e emissões monetárias; e (iii) diferenças entre receitas e despesas do governo. Observa-se a completude de sua análise ortodoxa ao abordar os três principais âmbitos da política econômica: produtivo, monetário e fiscal.

O principal mote de suas ideias e práticas, porém, foi a condução da política monetária, conforme será mais bem explorado na última seção do artigo. De forma esquemática, pode-se alocar Joaquim Murtinho entre os advogados da estabilidade cambial e monetária. Em discurso proferido no Senado Federal, em 1895, Murtinho já alertava para os riscos decorrentes da "superemissão de moedas e notas", tido por ele como "a pior forma de dívida interna" devido aos efeitos deletérios sobre a baixa do câmbio 5 . Ademais, a superabundância monetária levaria a um desenvolvimento industrial "sem ordem e sem estudo", permitindo o estabelecimento de indústrias $\operatorname{artificiais}^{6}$ e as condições para produção exagerada de café. Para solucionar este conjunto de problemas, Murtinho sugeria a seguinte estratégia:

A solução da questão econômico-financeira entre nós só se podia encontrar no restabelecimento da concordância daqueles elementos: reduzindo a produção do café e aumentando seu consumo, reduzindo a massa de papel-moeda e aumentando o valor da exportação, reduzindo a despesa pública e aumentando a receita, - operações todas estas duras, ásperas, irritantes, antipáticas, e às vezes mesmo com aparência de crueldade (MURTINHO apud LUZ, 1980, p. 218).

\footnotetext{
${ }^{5}$ Murtinho delegava ao Banco do Brasil, instituição, àquele momento, pública, a responsabilidade direta pela crise, defendendo, no mesmo relatório, a sua extinção.

${ }^{6}$ Em seu relatório de 1899, Murtinho define a indústria natural aquela que deve ser mantida no país, por apresentar capacidade de produzir o maior resultado possível em relação ao capital investido com o menor preço possível dentro de um regime concorrencial, independentemente de a matéria prima ser nacional ou importada. Afirma, ainda, que "o ideal econômico de um país não deve ser importar pouco, mas importar e exportar muito" (apud LUZ, 1980, p. 185).
} 
No que diz respeito especificamente ao principal vetor da crise do setor cafeeiro, a superprodução, Murtinho deixava transparecer suas convicções evolucionistas ao explicar como o governo teria solucionado a situação da lavoura: "O Governo deixou que a produção do café se reduzisse por seleção natural, determinando-se assim a liquidação e eliminação dos que não tinham condições de vida, ficando ela nas mãos dos mais fortes e dos mais bem organizados para a luta." (MURTINHO apud LUZ, 1980, p. 218).

Observa-se que, diferentemente do que se ocuparam os dois autores anteriores, Murtinho tratou de questões mais afeitas à condução da política econômica do que de assuntos morais. Sua formação técnica (engenheiro e médico) afastava-se da aura bacharelesca em que estavam envolvidos os debates do início do século XIX.

Como corolário desta breve análise do pensamento dos três personagens em tela, pode-se inferir a plausibilidade da tese seminal levantada por Schwarz (1992). Para este autor, o ideário liberal aportou em um país cujas instituições basilares depunham frontalmente contra as premissas básicas do liberalismo, tornando-se, aqui, uma ideologia fora de lugar. De acordo com Schwarz, mesmo após a abolição da escravidão, instituição que nega o mais básico princípio liberal, a relação entre homens livres ainda se dava através do favor, de relações arcaicas e de favoritismo. Ao adotar o favor como instituição regulatória das atividades do país, observava-se uma clara incompatibilidade da realidade brasileira com a ideologia liberal. Nos termos de Salomão (2013, p. 56):

Tratava-se da arbitrariedade subjacente ao favor o elemento responsável pela inaplicabilidade do liberalismo no Brasil. Instituição de aceitação 'quase universal' era tão incompatível com os ideais liberais quanto o escravismo, pois as absorvia e as deslocava, gerando, assim, um 'padrão particular'. Praticando a excessão à regra, o favor atribuía 'independência à dependência, utilidade ao capricho, universalidade às exceções, mérito ao parentesco, igualdade ao privilégio.

Ainda assim, não se pode negar a relevância da obra e da atuação dos autores apresentados como fator de transformação, ainda que marginal, do pensamento brasileiro. Fernandes (2006) define o "burguês" como ator social instrumentalizador do liberalismo, pois, ao procurar seus objetivos egoísticos acaba por personificar atores fundamentais do sistema capitalista: o homem de negócios e o industrial. Nesse sentido, Cairu defendia o fim da escravidão, Bastos apoiava a livre-iniciativa do recém-chegado imigrante e Murtinho atacava o favorecimento a certos setores produtivos. Conquanto não tenham feito de suas convicções políticas hegemônicas, suas ideias, mesmo que 
fora do lugar, foram fundamentais para estimular o debate político e intelectual no Brasil do século XIX.

\section{O Brasil na Divisão Internacional do Trabalho}

A argumentação dos autores liberais brasileiros quanto ao papel do país no sistema produtivo mundial baseava-se em duas ideias centrais: na teoria das vantagens comparativas e no conceito de "indústria natural". A partir das vantagens ricardianas de comércio, supõe-se que um país deve especializar-se naqueles bens em cuja produção apresente vantagens relativas aos outros países dadas as respectivas dotações de fatores. Já a "indústria natural” era aquela que poderia estabelecer-se e manter-se sem o apoio governamental, geralmente manufaturando produtos diretamente ligados ao setor primário.

Com o intuito de relacionar o pensamento liberal a essas duas questões, dividiuse a seção em duas partes. Em primeiro lugar, apresentar-se-ão as ideias de personagens selecionados a respeito de tais temas. A seguir, expor-se-á as propostas elencadas por uma das mais relevantes associações de classe do século XIX: a Sociedade Auxiliadora da Indústria Nacional (SAIN).

\subsection{O caminho do desenvolvimento: vocação agrária $\mathrm{x}$ industrialização}

Conforme apontado anteriormente, o visconde de Cairu dedicou-se à defesa do livre-comércio ao mesmo tempo em que analisou a plausibilidade do estabelecimento fabril em solo brasileiro. $\mathrm{O}$ autor publicou um tratado em que, além da já citada questão comercial, abordou outro tema caro aos liberais: produção industrial. O livro Observações sobre a franqueza da indústria, e estabelecimento de fábricas no Brasil, publicado em 1810, foi um dos principais pilares científicos utilizados pelos defensores da estratégia de desenvolvimento liberal.

A dotação de fatores - mão de obra e terra em abundância - de que dispunha o país fez com que Cairu, de fato, defendesse a chamada vocação agrária brasileira. Ainda assim, Cairu não se opunha ao estabelecimento industrial no Brasil, desde que este respeitasse a "natureza" da economia brasileira. Para o autor, não cabia ao Estado proteger artificialmente fábricas que não pudessem competir com as plantas que operavam no estado da arte. Se condizentes com a realidade local, as manufaturas decorrentes da produção primária seriam benéficas ao desenvolvimento econômico do 
país: "Que inumeráveis, e grandes conhecimentos não exigem a agricultura e mineração?" (LISBOA, 1999, p. 42).

Cairu recorria ao exemplo dos Estados Unidos, cuja história econômica assemelhava-se à estrutura produtiva brasileira em seus principais aspectos. Convictos de que não se podia concorrer com as fábricas inglesas ou francesas, Benjamin Franklin e Thomas Jefferson, por exemplo, defenderam que o investimento fosse direcionado à chamada "indústria agrária". Ainda assim, Cairu assentia à possibilidade de estabelecimento paulatino, e natural, do setor industrial, contanto que não afetasse os problemas da falta de capitais e de mão de obra da lavoura (FARIA JUNIOR, 2008).

Outro ator de formação liberal do fim século XIX que defendia a primazia da agricultura, mas ainda assim não se opunha ao estabelecimento manufatureiro no país foi Rui Barbosa. De acordo com Salomão e Fonseca (2015), Barbosa condenava políticas de proteção e favorecimento: "A indústria queixa-se, e definha. Que remédio lhe aconselham? A instrução? Não! O regime protetor; o protecionismo não passa de uma finta imposta ao consumidor em benefício de uma classe de produtores indígenas" (BARBOSA apud SALOMÃO; FONSECA, 2015, p. 155).

Observa-se, assim, que condizente com o que defendiam os clássicos, especialmente Smith e Malthus, os liberais brasileiros não se opunham diretamente ao estabelecimento do setor industrial. Se independente do ente público, a manufatura poderia representar um papel relevante para o desenvolvimento do país. O que se reprovava, em uníssono, era a proteção aduaneira e o favorecimento.

Tal entendimento pode ser comprovado por meio da aprovação do Código Comercial de 1850. Extrapolando a seara do comércio, o código contribuiu sobremaneira para o desenvolvimento do modo de produção capitalista no país ao estabelecer, dentre outras questões, prerrogativas dos direitos de propriedade. Bentivoglio (2002) analisa os debates que circunscreveram a aprovação do código e conclui que foram três as questões ao redor das quais se consolidou a política econômico no Segundo Reinado: organização da produção, do sistema financeiro e do comércio. Inscritas no processo de liberação de capitais, tais questões procuravam liberalizar a legislação econômica do país, opondo-se aos regulamentos portugueses herdados da época colonial. Sob influência direta de Princípios de direito mercantil e leis da marinha, obra de Cairu, o código buscava ratificar uma das necessidades básicas para o bom funcionamento do capitalismo: a confiança nos contratos e transações. 


\subsection{A Sociedade Auxiliadora da Indústria Nacional (SAIN)}

A SAIN foi a primeira associação industrial inaugurada no país, em 1827. Criada como órgão consultivo do Império, inspirou-se nos homônimos franceses e portugueses $^{7}$, e explicitava em seu estatuto inaugural o objetivo de "promover o melhoramento e prosperidade da Indústria no Império do Brasil" (BARRETO, 2009, p. $58)^{8}$. Importante divulgadora da ciência no país por meio de seu periódico $O$ Auxiliador da Indústria Nacional, a Sociedade contava com a colaboração de cientistas, homens de negócio, burocratas e homens das letras (BARRETO, 2008).

Azevedo (2011) analisa a posição da Sociedade por meio de seus estatutos até a cisão da subseção fabril, na década de 1870. A despeito de carregar o termo "industrial" em sua insígnia, fazia-se clara a posição da instituição quanto à chamada "indústria agrícola":

A Indústria, mãe de todas as ciências e artes, e causa primária da opulência e grandeza das Nações, em geral se reduz à ação das forças físicas e morais do homem aplicadas à produção. Quando se tem por objetivo maior desenvolvimento das forças naturais, ou a colheita dos produtos que o Criador espontaneamente nos apresenta, dá-se-lhe o nome de agrícola; quando se tem por fim dar novas formas às produções da natureza, submetendo-as complicados processos para que estas nos sejam mais úteis, chama manufatureira; e se um valor qualquer procura-se dar aos produtos tanto naturais como artefatos, e os leva aos mercados para serem consumidos, denomina-se comercial. Ora, se em países bem povoados parece que a experiência mostra a impossibilidade de se cultivarem, com o mesmo esmero, os três ramos de indústria, evidentemente se manifesta que com muito mais razão o Brasil, com uma diminuta população disseminada em vastíssima superfície, deve escolher um ramo especial, sem, todavia, abandonar os outros. Qual deve ser entre nós este ramo, altamente a esta proclamando a fertilidade de nosso abençoado território. Por longos anos cumpre, pois que seja o Brasil muito especialmente agricultor (STURZ apud AZEVEDO, 2011, p. 28).

Essa posição oficial foi mantida durante praticamente toda a existência da SAIN.

Observou-se divergência, contudo, quando da ocorrência de crises setoriais, como a chamada "crise do chapéu", na década de 1870. A seção industrial do órgão

\footnotetext{
${ }^{7}$ Mais especificamente na francesa Societé D'Encouragement à L'Industrie Nationale, e na portuguesa Sociedade Promotora da Indústria Nacional (BARRETO, 2008).

${ }^{8}$ Vale retomar a ideia de que, à época, o termo "indústria" não era utilizado exclusivamente para manufaturas. De modo que a defesa da "prosperidade industrial" não pode ser entendida em sua acepção atual, pois o objetivo da sociedade focava o desenvolvimento da indústria agrícola e suas tecnologias.

${ }^{9}$ De acordo com Luz (1975, p. 51), na década de 1870 as fábricas de chapéus brasileiras passaram a sofrer concorrência alemã, cujos produtos apresentavam qualidade similar a preços mais baixos. Em 
posicionou-se a favor dos chapeleiros, afirmando, em parecer oficial, que o liberalismo estava "condenando o país ao abismo" (LUZ, 1975, p. 53). Já para seção a comercial da SAIN, o argumento ricardiano mantinha-se válido, de modo que a derrocada dos produtores de chapéus brasileiros devia-se à ineficiência de suas estruturas produtivas. O conflitou resultou, anos depois, na implosão da sociedade e na criação da Associação Industrial do Rio de Janeiro por parte dos defensores da atividade fabril. Seu fim, porém, não matizou a importância de suas atividades ao longo do século XIX, as quais, em alguma medida, contribuíram para o fortalecimento do ideário e, mais precisamente, das políticas liberais no Brasil oitocentista.

\section{O debate monetário no século XIX}

Se o liberalismo brasileiro fez-se presente nos mais diferentes debates políticos daquele momento, foi na seara monetária que a ortodoxia liberal encontrou seu mais eloquente meio de representação. O debate monetário brasileiro ao longo do século XIX sofreu grande influência das discussões que ocorriam na maior e mais importante economia da época, a Inglaterra. Apesar das peculiaridades locais, dada a diferença nos estágios de desenvolvimento dos dois países, a essência da contenda circunscrevia duas principais questões: as controvérsias entre bulionistas e antibulionistas, e as que separavam os defensores da banking school e da currency school ${ }^{10}$ (FONSECA; MOLLO, 2012).

De modo a introduzir o assunto, faz-se relevante destacar um princípio fundamental para o entendimento dos debates monetários: a Teoria Quantitativa da Moeda (TQM). Tal princípio parte da identidade MV=PY, na qual M é a quantidade de moeda, $\mathrm{P}$ o nível geral de preços, $\mathrm{V}$ a velocidade de circulação da moeda e $\mathrm{Y}$ o produto real. Para os adeptos da TQM, a variável "V" é constante e a "Y" não é afetada por políticas monetárias, do que se conclui que há uma relação direta entre a quantidade de moeda em circulação (M) e o nível de preços $(\mathrm{P})$. No cerne do debate, a TQM dividiu papelistas e metalistas acerca da prescrição de políticas econômicas a serem adotadas no decorrer do século XIX.

busca de auxílio, os fabricantes de chapéu enviaram um manifesto para a SAIN, trazendo discordâncias internas entre as seções de comércio e indústria.

${ }_{10}$ Muitos dos argumentos do debate posterior entre a Currency School e a Banking School foram inspirados por este primeiro debate entre bulionistas e antibulionistas, tendo a Currency School afinidade com os argumentos bulionistas e a Banking School com os levantados pelos antibulionistas. 


\subsection{O debate europeu}

De acordo com Mollo (1994), os bulionistas - tais como Wheatley, Lauderdale e Ricardo - defendiam que a desvalorização do bullion em relação ao valor do ouro cunhado sinalizava depreciação das notas bancárias, pois estas eram emitidas em excesso. Disso resultava a necessidade de se controlar a emissão das notas bancárias, sendo um dos principais meios a liberação de ouro para o mercado externo. Essa medida faria com que os preços no país importador de ouro aumentassem, fazendo com que o país exportador contasse com mais moeda em circulação; assim, não haveria prêmios sobre o bullion, ao mesmo tempo em que ocorreria um ajustamente automático no balanço de pagamentos.

Já para os antibulionistas (como Boase, Bosanquet e Trotter), o aumento de preços não era causado pelo excesso de emissão de notas bancárias. Estes argumentavam que fatores como a velocidade de circulação da moeda - constante para os bulionistas - poderia afetar seu valor, contradizendo os princípios da TQM. Outro ponto de divergência era a afirmação dos antibulionistas de que havia lastro das notas bancárias em bens reais, não sendo possível, pois, excesso de emissão. Assim, o aumento de preços seria a causa da elevação de moeda em circulação, invertendo a relação causal defendida pelos bulionistas ${ }^{11}$.

Já a banking school defendia o princípio bancário, pelo qual as emissões de notas bancárias só deveriam servir como meio de efetivar acordos comerciais já realizados, sendo o aumento de emissões simples reflexo do aumento das transações ${ }^{12}$. Os adeptos da currency school, por sua vez, acreditavam no chamado princípio monetário, ou seja, aceitavam de forma estrita a TQM. Seus defensores pregavam políticas monetárias ainda mais restritivas do que os bulionistas, buscando uma situação em que os meios de circulação seriam uma contrapartida direta das moedas metálicas. Em outras palavras, a quantidade de moeda circulante deveria aumentar sempre que houvesse ingresso de ouro no país, e decrescer, caso contrário.

As divergências expostas influenciaram diretamente o debate sobre (e a condução da) política monetária no Brasil, onde as controvérsias circunscreviam duas

\footnotetext{
${ }^{11}$ Faz-se relevante notar que ambas escolas estavam de acordo em duas questões de longo prazo: o valor da moeda é determinado pelo custo de produção de ouro e a conversibilidade-ouro das notas bancárias era essencial. As diferenças se davam na análise acerca de variáveis afetadas no curto prazo, apenas.

12 Para os adeptos desta escola, a emissão de papel-moeda poderia ter viés inflacionário. Já a emissão de notas bancárias não tinha este efeito por ser baseada em relações entre bens reais estabelecidas anteriormente à sua emissão. Por estes motivos, as notas bancárias deveriam ser tratadas de modo diferenciado.
} 
questões: o direito de emissão e o tipo de conversibilidade em ouro que deveria ser exigido. Quanto ao primeiro, discutia-se se este deveria ser cedido a um banco central (posição da currency school) ou a diversos bancos concorrentes (banking school). Ademais, discutia-se se tais bancos deveriam ser públicos ou privados ${ }^{13}$. Quanto à questão da conversibilidade, a polêmica girava em torno da natureza das reservas: se estas deveriam basear-se somente em ouro - ideia apoiada pela currency school - ou se poderiam incluir notas do tesouro e ações de empresas, como defendido pela escola bancária.

\subsection{Reprodução do debate monetário no Brasil}

O debate brasileiro reproduzia diretamente o que se discutia na Europa. De um lado, os metalistas, defensores do princípio monetário; do outro, os papelistas, adeptos do princípio bancário. Tendo por objetivo sistematizar os argumentos liberais defendidos pela ortodoxia metalista, apresentar-se-ão os principais argumentos expostos por homens de clara convicção metalista, tais como Rodrigues Torres, Silva Ferraz, Torres Homem, Dias de Carvalho e Francisco Belisário Soares de Souza.

Baseada no princípio monetário, a crítica metalista ao tipo de meio circulante brasileiro da época diz respeito à falta de lastro metálico, já que este é o garantidor de valor intrínseco da moeda e de sua estabilidade (GREMAUD, 1997). No entanto, os metalistas reconheciam o argumento papelista quanto às diferenças entre as situações das reservas de metais em países como a Inglaterra e o Brasil, onde a escassez de reserva foi a regra durante quase todo o século XIX. Desse modo, os metalistas recomendavam a adoção de políticas de atração de metais preciosos, aliadas ao incentivo à produção de ouro. Além disso, deveria conter-se a emissão monetária, pois, se observada a lei de Gresham ${ }^{14}$, a exportação de moedas "boas" deporia ainda mais com a escassez de lastro.

As duas escolas admitiam a necessidade de a moeda ser conversível em metais. O que as separava era a aceitação ou não de títulos da dívida como lastro, conforme defendiam os papelistas. Rodrigues Torres, político de reconhecidas convicções

\footnotetext{
${ }^{13}$ Os adeptos da Currency School acreditavam que a emissão de moedas deveria ser operada por um só banco controlado pelo Estado. Para estes, a emissão por vários agentes através de processo concorrencial teria caráter inflacionário, justificando a intervenção estatal neste caso.

${ }^{14}$ De acordo com este princípio, se duas moedas, contendo diferentes quantidades metais, tiverem o mesmo valor legal, aquela que tiver menor valor metálico será usada para a troca e a outra será entesourada ou exportada. O princípio pode ser resumido na frase: "moeda ruim expulsa moeda boa".
} 
metalistas, expunha, em sessão na Câmara dos Deputados, suas as preocupações com o que ele considerava uma emissão exagerada:

Eu não desconheço, que alguns economistas teóricos, entre os quais seja-me permitido citar o nome de Ricardo, entendem que a moeda mais perfeita é o papel; mas observe que esses economistas falam do papel realizável, papel com garantias sólidas e não do papel-moeda que temos. Observarei mais que, conquanto seja inconveniente deslocar capitais dos empregos produtivos para serem empregados como instrumentos de circulação, é também fora de dúvida que a tranquilidade e segurança dos negócios de comércio exigem que esse instrumento tenha valor real e intrínseco (TORRES apud GAMBI, 2011, p. 11).

No que tangia à concessão de crédito, os metalistas também demonstravam parcimônia da Currency School. O então deputado Torres Homem advertia que a facilidade do crédito não é a necessidade primordial do comércio, mas a sua solidez e permanência. Quanto à questão dos altos juros e seus efeitos sob a população, o parlamentar argumentava que a taxa de juros não era determinada pela política monetária, já que esta é somente influenciada por uma relação entre oferta e demanda de capitais.

Das discussões travadas acerca da conversibilidade e sua influência sobre a solidez da moeda, os metalistas puderam a teoria que professavam na adoção de política pública em situações muito específicas. A realidade das divisas brasileiras impedia que tal conversibilidade estrita pudesse ser mantida tempo contínuo. Quanto à questão da pluralidade ou centralidade da emissão, contudo, diversos foram os momentos em que os metalistas defenderam seus argumentos com base na práxis dos homens, uma vez que a autoridade monetária ficou centralizada (muitas vezes a cargo de entidades privadas, é verdade) por longos períodos.

Segundo Gambi (2011), Rodrigues Torres provavelmente foi o mais relevante político na defesa do ideário metalista na sua época, tendo papel fundamental na defesa da centralidade emissora. Para Torres, vários bancos emissores resultariam em excitamento perigoso das atividades comerciais, ensejando operações de alto risco. Isto se devia ao fenômeno da concorrência bancária, pois tal processo de disputa por maior número possível de clientes fazia baixar os juros de maneira excessiva, levando empresas sem a qualificação operacional necessária a tomarem crédito de alto risco, naquilo que o político denominava de captais "fictícios e de imaginação".

Além disso, assim como os integrantes da Currency School, os metalistas acreditavam que as notas bancárias tinham efeitos inflacionários similares ao papel- 
moeda. Desse modo, por defenderem o enxugamento do meio circulante, tinham como inócua a permissão para que os bancos emitirem notas, pois esta negaria o efeito da diminuição de papel-moeda circulante. Por estes motivos, acreditava que o controle do volume de moeda e crédito circulando deveria ser de responsabilidade de um único banco público, não diversos bancos privados.

Um dos principais homens públicos que se opuseram à lógica monetária ortodoxa-liberal foi Bernardo de Souza Franco, ministro da Fazenda enquanto Rodrigues Torres era presidente do Banco do Brasil. Na obra Os Bancos do Brasil, Franco alinhava-se ao papelistas ao defender que a emissão de notas era somente uma consequência das operações já ocorridas na economia real (GREMAUD, 1997, p. 7). Quando à frente da Fazenda, Souza Franco patrocinou uma política de pluralidade de emissão, a qual não resistiu à crise de carestia de 1857-1858, sendo, logo em seguida, abandonada pelo gabinete conservador que assumiu o governo.

Conforme argumentado, o debate monetário brasileiro baseou-se nos argumentos utilizados pelos europeus havia algum tempo. Algumas questões, porém, sofreram influências devido às particularidades da economia brasileira, tais como o pequeno volume de reservas e a baixa institucionalização das casas bancárias. A corrente liberal (metalista) parece ter subestimado o peso de tais especificidades, defendendo de forma deslocada princípios que não se adaptavam à realidade nacional.

\section{Considerações finais}

O liberalismo encontrou no Brasil um ambiente significativamente diferente daquele em que fora gestado. Se do ponto de vista econômico pode-se afirmar que o Brasil adotou, de fato, um modelo liberal, a realidade escravocrata não autorizava o estabelecimento pleno dessa ideologia no país. Fora de lugar, o liberalismo serviu aos interesses da elite rural, em primeiro lugar, e dos traficantes de escravos, fração de classe de poder ascendente no início do século XIX, em segundo,. O liberalismo foi utilizado, inclusive, para justificar a manutenção do cativeiro. Tratando-se o escravo de um ativo do senhor, o direito de propriedade - fundamento basilar do liberalismo deveria ser garantido e defendido, sob risco de se subverter a ordem estabelecida havia três séculos.

Os autores analisados na primeira seção do trabalho sumarizam de forma esquemática pelo menos três dos principais assuntos de que se ocupavam os liberais no 
Brasil daquele momento: liberdade comercial, livre movimentação de um dos fatores de produção (trabalho) e conversibilidade da moeda em ouro, conforme estabelecido pelo sistema do padrão-ouro.

Se o primeiro mote influenciou diretamente a política de abertura dos portos após a chegada da família Real, em 1808, a segunda questão, defendida especialmente por Tavares Bastos, só se tornou política pública diante da necessidade premente por braços dos cafeicultores paulistas diante do encarecimento do escravo. A chegada de milhões de imigrantes também respondeu à lógica das teorias raciais vigentes àquele momento, visando, paralelamente, ao embranquecimento da população brasileira.

Por fim, ainda que não se possa classificar os adeptos do metalismo como liberais no sentido lato do termo - sendo mais correto do ponto de vista conceitual designá-los como ortodoxos -, os defensores da moeda conversível partiam de uma premissa cara ao liberalismo: a impressão de moeda deveria obedecer às condições impostas pelo balanço de pagamentos. Aumentar-se-ia a circulação monetária se, e somente se, houvesse a entrada de divisas para que nestas a moeda fosse lastreada.

Sabe-se que o liberalismo jamais se firmou como ideologia hegemônica no Brasil independente. Ainda assim, diversos de seus postulados foram utilizados para embasar a adoção de políticas as quais beneficiassem setores sociais dominantes. Empregado de forma seletiva, o liberalismo não logrou beneficiar o conjunto da sociedade brasileira como o fez em outras economias, enfrentando, até a contemporaneidade, resistências para suplantar o debate acadêmico e transformar-se em política pública.

\section{Referências}

ALVES, Andreia F. Visconde de Cairu - Civilidade, Escravidão e Barbárie. VIII Simpósio Internacional Processo civilizador, História e Educação, 2004.

AZEVEDO, Jussara F. de. Discursos e idéias. A gênese da luta pelo processo de organização da indústria no Brasil: a Associação Industrial do Rio de Janeiro e sua luta pela indústria nacional no século XIX (1870-1888). 2011. 199 f. Dissertação (Mestrado) - Curso de História Social, Universidade do Estado do Rio de Janeiro, São Gonçalo, 2011.

BARRETO, Patrícia Regina C. Sociedade Auxiliadora da Indústria Nacional: Oficina de Homens. XIII Encontro de História, Anpuh, Rio de Janeiro, p.1-8, ago. 2008. 
BARRETO, Patrícia Regina C. Sociedade Auxiliadora da Indústria Nacional: o templo carioca de Palas Atena. 2009. 385 f. Tese (Doutorado) - Curso de História das Ciências e das Técnicas e Epistemologia, Universidade Federal do Rio de Janeiro, Rio de Janeiro, 2009.

BENTIVOGLIO, Júlio César. O império das circunstâncias: o Código Comercial e a política econômica brasileira (1840-1860). 2002. 290 f. Tese (Doutorado) - Curso de História Econômica, Universidade de São Paulo, São Paulo, 2002.

FARIA, Fernando Antonio. Joaquim Murtinho: criadores e criatura. Intellectus, Rio de Janeiro, v. 1, n. 04, p.1-10, 2005.

FARIA JUNIOR, Carlos de. O Pensamento Econômico de José da Silva Lisboa, Visconde de Cairu. 2008. 352 f. Tese (Doutorado) - Curso de História Econômica, Universidade de São Paulo, São Paulo, 2008.

FERNANDES, Florestan. A revolução burguesa no Brasil. São Paulo: Zahar, 2006.

FONSECA, Pedro Cezar D. Keynes: O Liberalismo Econômico como Mito. Economia e Sociedade, Campinas, v. 19, n. 3, p.425-447, dez. 2010.

FONSECA, Pedro Cezar D. MOLLO, Maria de Lourdes R. Metalistas x papelistas: origens teóricas e antecedentes do debate entre monetaristas e desenvolvimentistas. Nova Economia, Belo Horizonte, v. 22, n. 2, p.203-233, maio 2012.

GAMBI, Thiago F. R. O segundo Banco do Brasil como banco da Ordem. In: Simpósio Nacional de História, 26. São Paulo: Anpuh, 2011.

GREMAUD, Amaury Patrick. Das controvérsias teóricas à política econômica: pensamento econômico e economia brasileira no Segundo Império e na Primeira República (1840-1930). 1997. 265 f. Tese (Doutorado) - Curso de Economia, Faculdade de Economia, Administração e Contabilidade, Universidade de São Paulo, São Paulo, 1997.

GUGLIOTTA, Alexandre Carlos. Entre trabalhadores imigrantes e nacionais: Tavares Bastos e seus projetos para a nação. 2007. 189 f. Dissertação (Mestrado) - Curso de História Social, Universidade Federal Fluminense, Niterói, 2007.

LISBOA, José da S. Observações Sobre a Franqueza da Indústria e Estabelecimento de Fábricas no Brasil. Brasília: Senado Federal, 1999.

LUZ, Nícia V. A luta pela industrialização do Brasil. São Paulo: Alfa-omega, 1975.

LUZ, Nícia V. Ideias econômicas de Joaquim Murtinho. Brasília: Senado Federal, 1980.

LYNCH, Christian Edward C. O Conceito de Liberalismo no Brasil (1710-1810). Araucária: Revista Iberoamericana de filosofia, política y humanidades, Sevilla, v. 1, n. 17, p.212-234, maio 2007. 
MOLLO, Maria de Lourdes R. As Controvérsias Monetárias do Século XIX. Ensaios FEE, Porto Alegre, v. 15, n. 1, p.80-97, abr. 1994. Trimestral.

MONTEIRO, Pedro M. Um moralista nos trópicos: o visconde de Cairu e o duque de la Rochefoucauld. 2001. 285 f. Tese (Doutorado) - Curso de Teoria e História Literária, Unicamp, Campinas, 2001.

PAIM, Antonio. História do Liberalismo Brasileiro. Rio de Janeiro: Mandarim, 1998.

SALOMÃO, Ivan C. O desenvolvimento em construção: um estudo sobre a pré-história do pensamento desenvolvimentista brasileiro. 2013. $190 \mathrm{f}$. Tese (Doutorado) - Curso de Economia, Universidade Federal do Rio Grande do Sul, Porto Alegre, 2013.

SALOMÃO, Ivan C.; FONSECA, Pedro Cezar D. Heterodoxia e industrialização em contexto agrário-exportador: o pensamento econômico de Rui Barbosa. América Latina En La Historia Económica, México, v. 22, n. 1, p.150-178, jan./abr. 2015.

SCHWARZ, Roberto. As ideias fora do lugar. In: SCHWARZ, Roberto. Ao Vencedor as Batatas. São Paulo: Duas Cidades, 1992.

SILVA, Ligia Osório. Tavares Bastos e a Questão Agrária no Império. História Econômica \& História das Empresas, v.1, n.1, São Paulo, 1999.

SMITH, Adam. A riqueza das nações: Investigação sobre sua Natureza e suas Causas. São Paulo: Nova Cultural, 1996. 